\title{
In Vitro Biocompatibility Evaluation of Nine Dermal Fillers on L929 Cell Line
}

\author{
Vincenza Cannella ${ }^{(D)}{ }^{1}$ Roberta Altomare $\left(\mathbb{D},{ }^{1}\right.$ Vincenza Leonardi ${ }^{(D)},{ }^{2}$ Laura Russotto ${ }^{(D)}{ }^{1}$ \\ Santina Di Bella $₫{ }^{1}$ Francesco Mira $\left({ }^{1},{ }^{1}\right.$ and Annalisa Guercio ${ }^{1}{ }^{1}$ \\ ${ }^{1}$ Istituto Zooprofilattico Sperimentale della Sicilia “A. Mirri”, Via Gino Marinuzzi, 3-90129 Palermo (PA), Italy \\ ${ }^{2}$ Department of Psychology, Pedagogy and Sports Sciences, AOUP Paolo Giaccone, University of Palermo, Italy \\ Correspondence should be addressed to Vincenza Cannella; vincenza.cannella@izssicilia.it
}

Received 20 March 2020; Revised 16 April 2020; Accepted 17 April 2020; Published 27 May 2020

Academic Editor: Giuseppina Nocca

Copyright (C) 2020 Vincenza Cannella et al. This is an open access article distributed under the Creative Commons Attribution License, which permits unrestricted use, distribution, and reproduction in any medium, provided the original work is properly cited.

\begin{abstract}
Objective. Biomaterial research for soft tissue augmentation is an increasing topic in aesthetic medicine. Hyaluronic acid (HA) fillers are widely used for their low invasiveness and easy application to correct aesthetic defects or traumatic injuries. Some complications as acute or chronic inflammation can occur in patients following the injection. Biocompatibility assays are required for medical devices intended for human use, in order to prevent damages or injuries in the host. In this study, nine HA fillers were tested in order to evaluate their cytotoxicity and their effects on L929 cell line, according to the UNI EN ISO 10993 regulation. Methods. Extracts were prepared from nine HA fillers, and MTS viability assay was performed after $24 \mathrm{~h}, 48 \mathrm{~h}$, and $72 \mathrm{~h}$ of exposure of cells to extracts. Cells cultured with HA filler extracts were monitored for up to $72 \mathrm{~h}$, counted, and stained with haematoxylin/eosin in order to evaluate the cell proliferation rate and morphology. Results. None of the filler tested showed a cytotoxic effect. Two samples showed a higher vitality percentage and higher cell number while two samples showed a lower vitality percentage and lower cell number at $72 \mathrm{~h}$. Conclusion. Data obtained suggest that although examined fillers are not cytotoxic, they show different effects on the in vitro cell proliferation rate. In vitro studies of medical devices could lead to important implications since these could aid to predict effects about their in vivo application. These easy and rapid assays could be useful to test new materials intended for human use avoiding animal tests.
\end{abstract}

\section{Introduction}

In the last few years, biomaterial research for soft tissue augmentation has been implemented for its application for the correction of serious and slight aesthetic defects or traumatic injuries [1]. Injectable fillers are widely used for their low invasiveness and easy application. Fillers, as medical devices, must be biocompatible by inducing an appropriate biological response in a specific application, without causing damage or injury [2]. This involve an interaction between the host environment, the material, and the function that it must perform. Biocompatibility is a dynamic process aimed at minimizing any adverse reaction or rejection by the host [3]. Since a filler integrates with the body, skin, and derma, the interaction of the material with the surrounding tissues could be responsible of many biological reactions. Based on their chemical composition, they can be classified into "biological fillers" and "synthetic fillers". The first ones consist on natural molecules that undergo skin resorption after a certain period of time. They are represented by collagen, hyaluronic acid, and polylactic acid. The "synthetic fillers" are derived from synthesis processes, and their effect is more prolonged compared to biological fillers. The most common synthetic fillers are polyacrylamide, polymethylmethacrylate, polytetraethylene, and povidone. Therefore, according to their longevity, fillers can be permanent or temporary. The main advantage from the use of fillers is obtaining harmonious and natural results immediately, without resorting to invasive surgical procedures. However, acute inflammatory reactions are the most frequent complications that occur immediately following the injection. Other complications are granulomas, herpes labialis, permanent redness, small necrosis, or abscesses. 
Chronic inflammations could occur after a certain period $[4,5]$. Hyaluronic acid (HA) is one of the most common naturally derived filler, and, nowadays the most frequently used, even if its short persistence, possible allergenicity, and immunogenicity leads to the research of new synthetic materials [5]. HA is an anionic, nonsulphated glycosaminoglycan widely represented in connective, epithelial, and neural tissues. HA is one of the major components of the skin, and it is involved in tissue regeneration, due to its high water-binding properties, maintaining proper tissue volume. Impair of HA promotes biological ageing and wrinkle development. A variety of HA-based fillers has been approved for the treatment of wrinkles, scars, and facial contouring defects [6]. HA used to produce fillers is synthesized in laboratory from bacterial cultures. In order to guarantee an adequate permanence once injected into the tissues, HA chains undergo a crosslinking process with linking substances, which ensure a greater resistance to the action of enzymes in the body. One of the most used linking substances is BDDE (1,4-butanediol diglycidyl ether) [5].

HA dermal fillers are classified into two categories, monophasic or biphasic. The monophasic ones consist of solid particles of material, plunged in a fluid carrier substance, and appear as a homogeneous gel. Biphasic fillers are composed of cross-linked HA particles immersed in a fluid matrix consisting of low or zero cross-linked HA. Monophasic HA fillers are more cohesive, may last longer, and show a low migration rate after injection; biphasic HA fillers are more easily customized and adaptable to the anatomical area being treated [7].

A filler must be similar to the native tissue, durable, easily implantable, and painless for the patient. Moreover, it should be nontoxic, noncarcinogenic, inert, nonallergic, nonimmunogenic, nonpyrogenic, and nonmigrating [2]. For this reason, marketing of any device, intended for human use, requires the assessment of the biological response [8]. The evaluation of cytotoxicity is a crucial step to establish the biocompatibility of a material $[9,10]$. The European Directive 63/2010/EU, defines the concept of 3Rs (Replacement, Reduction and Refinement) addressing the interest of the scientific community towards the application of in vitro methods as alternatives approach to the in vivo methods [11]. The interaction of cell cultures with potential toxic compounds released by a biomaterial induces a detectable biological response through which it is possible to establish the safety of a material under examination. Cytotoxicity tests allow to highlight the possible alterations in basic cellular functions through the analysis of cellular metabolism, morphology, and the proliferation rate or vitality [12]. The UNI EN ISO $10993 / 2009$ rule, part five, describes suitable in vitro methods to perform the biological evaluation of medical devices [13]. Tests can be performed through a direct or indirect contact of cells with the material or through a contact with an extract, depending on the nature and the shape of the material under examination. [14-16]. Medical devices, including fillers for aesthetic medicine, are not subject to any prior authorization from the Competent Authority (Ministry of Health), as there is a European regulation of "new approach", according to
TABLE 1: Characteristics of the nine HA fillers used.

\begin{tabular}{|c|c|}
\hline Samples & Description \\
\hline Filler 1 & $\begin{array}{c}\text { Stabilized hyaluronic acid } 20 \mathrm{mg} / \mathrm{ml} \text {, nonanimal } \\
\text { origin, pH } 6-7.5 \text { biphasic }\end{array}$ \\
\hline Filler 2 & $\begin{array}{c}\text { Cross-linked hyaluronic acid } 20 \mathrm{mg} / \mathrm{ml} \text { with lidocaine } \\
\text { hydrochloride } 3 \mathrm{mg} / \mathrm{ml} \text {, biphasic }\end{array}$ \\
\hline Filler 3 & $\begin{array}{l}\text { Hyaluronic biorevitalizing gel, medium-chain } \\
\text { hyaluronic acid } 20 \mathrm{mg} / \mathrm{ml} \text { in a physiologic buffer, } \\
\text { produced from Streptococcus equi bacteria }\end{array}$ \\
\hline Filler 4 & $\begin{array}{l}\text { Hyaluronic acid } 20 \mathrm{mg} / \mathrm{ml} \text {-sodium chloride } \\
16 \mathrm{mg} / \mathrm{ml} \text {, from bacterial biofermentation, BDDE } \\
\text { cross-linking agent, monophasic }\end{array}$ \\
\hline Filler 5 & $\begin{array}{l}\text { Reticulated hyaluronic acid } 25 \mathrm{mg} / \mathrm{ml} \text { with lidocaine } \\
\text { hydrochloride } 3 \mathrm{mg} / \mathrm{ml} \text {, animal origin, } \mathrm{pH} 7.2\end{array}$ \\
\hline Filler 6 & $\begin{array}{l}\text { Reticulated hyaluronic acid } 24 \mathrm{mg} / \mathrm{ml} \text { in physiological } \\
\text { buffered saline, from biotechnological fermentation, } \\
\text { low BDDE content, monophasic }\end{array}$ \\
\hline Filler 7 & $\begin{array}{l}\text { Auto cross-linked hyaluronic acid-sodium chloride } \\
\qquad 18 \mathrm{mg} / \mathrm{ml}\end{array}$ \\
\hline Filler 8 & $\begin{array}{l}\text { Hyaluronic acid } 2 \mathrm{mg} \text { and cross-linked HA } 20 \mathrm{mg}- \\
\text { sodium chloride } 6.9 \mathrm{mg} \text {, nonanimal origin, } \\
\text { endotoxin- and BDDE-free }\end{array}$ \\
\hline Filler 9 & $\begin{array}{l}\text { Cross-linked hyaluronic acid } 20 \mathrm{mg} / \mathrm{ml} \text {-lidocaine } \\
\text { hydrochloride } 3 \mathrm{mg} / \mathrm{ml} \mathrm{pH} \mathrm{7,} \mathrm{biphasic}\end{array}$ \\
\hline
\end{tabular}

which medical devices are certified by notified bodies authorized in the European Country [17].

This study is aimed at evaluating the biocompatibility of nine commercially available different HA fillers by performing a cytotoxicity test and cell proliferation test on the L929 cell line.

\section{Materials and Methods}

2.1. Samples. Samples used were nine different HA fillers commercially available with an average content of $20 \mathrm{mg} / \mathrm{ml}$ HA. Filler samples arrived in the laboratory sealed in their packaging, and sterility was guaranteed by the manufacturer. More detailed characteristics of each filler are described in Table 1.

2.2. Cell Culture. L929 cell line (murine fibroblast) was purchased from Cell Bank of National Reference Institute for Alternative Methods, Welfare and Care of Laboratory Animals (Istituto Zooprofilattico Sperimentale della Lombardia ed Emilia Romagna, Italy). Cells were grown in culture flasks containing minimum essential medium (MEM, SigmaAldrich), supplemented with $10 \%$ fetal bovine serum (FBS, Euroclone), $1 \%$ antibiotic-antimycotic solution (SigmaAldrich), and $1 \%$ nonessential amino acids (NEAA, Euroclone). Cells were maintained at $+37^{\circ} \mathrm{C}$ in a humidified $5 \% \mathrm{CO}_{2}$ atmosphere and monitored daily by using an inverted microscope. Subcultures were performed twice a week, when an $80 \%$ of confluence was observed.

2.3. Sample Preparation. The "extraction dilution method" was chosen as described by the UNI EN ISO 10993 regulation [13]. Extraction procedure was carried out in an extraction 


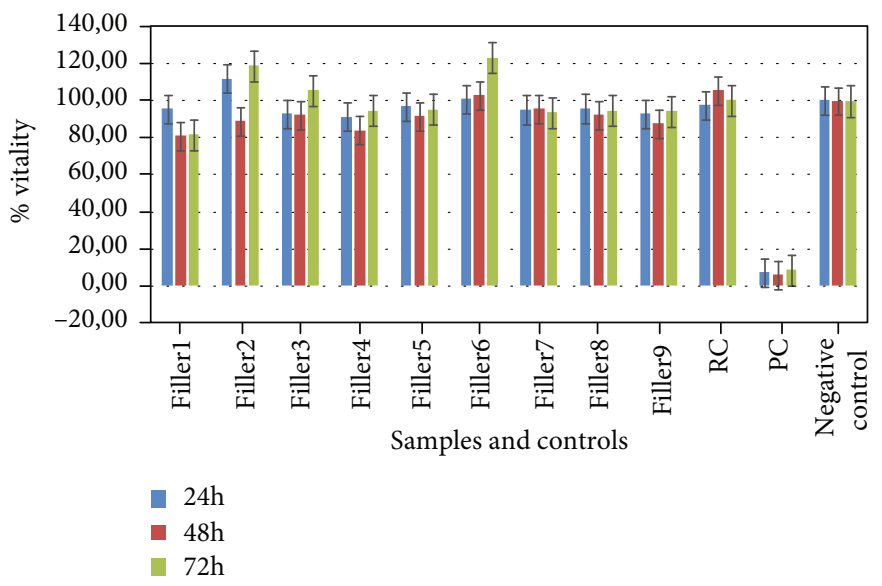

Figure 1: Effects of HA filler extracts and controls on L929 cells at $24 \mathrm{~h}, 48 \mathrm{~h}$, and $72 \mathrm{~h}$ of exposure. Data express the percentage of cell viability.

medium consisting of MEM, supplemented with $10 \%$ FBS, $1 \%$ antibiotic-antimycotic solution, and $1 \% \mathrm{NEAA}$ at $+37^{\circ} \mathrm{C}$ \pm 1 for $24 \mathrm{~h}$, by continuous agitation. An amount of $0.2 \mathrm{~g}$ of each filler was dissolved in $1 \mathrm{ml}$ of extraction medium. The extraction medium without sample was used as reagent control (RC) and treated as a sample. A 5\% phenol solution was used as positive control (PC).

2.4. Cytotoxicity Test on the L929 Cell Line. Cells were seeded into 96 -well culture plates at $1 \times 10^{5}$ cells/ml ratio in MEM, supplemented with $10 \%$ FBS, $1 \%$ antibiotic-antimycotic solution, and $1 \%$ NEAA. Three 96-well culture plates for each filler were prepared and incubated at $+37^{\circ} \mathrm{C} \pm 1$ in $5 \% \mathrm{CO}_{2}$ for $24 \mathrm{~h}$. After this time, culture media were replaced with $100 \mu \mathrm{l}$ of each filler extract and the control extracts and a series of twofold dilutions (from $100 \%$ to $3,125 \%$ concentrations). The assay was carried out in triplicate. Moreover, intralaboratory assays were performed. Some wells were filled with MEM, supplemented with 10\% FBS, 1\% antibiotic-antimycotic solution, and 1\% NEAA, and used as control cells (negative control). All plates were incubated at $+37 \pm 1^{\circ} \mathrm{C}$ in a $5 \% \mathrm{CO}_{2}$ atmosphere and examined microscopically after $24 \mathrm{~h}, 48 \mathrm{~h}$, and $72 \mathrm{~h}$ of incubation in order to assess vitality and general morphology of cells. The vitality MTS assay was performed at the same time points as previously described [12]. The absorbance recorded is directly proportional to the number of living cells. All samples and controls were compared with negative control to calculate the percentage of vital cells, using the following equation:

$$
\text { Viab } \%=100 \times \frac{O \cdot D_{490 e}}{O \cdot D_{490 b}} \text {, }
$$

where O.D $\mathrm{D}_{490 \mathrm{e}}$ is the mean value of the measured optical density of extracts and O.D $\mathrm{D}_{490 \mathrm{~b}}$ is the mean value of the measured optical density of the negative control. A sample is considered cytotoxic if the percentage vitality value is $<70 \%$ and noncytotoxic if the percentage vitality value is $>70 \%$.

2.5. Proliferation Test on the $L 929$ Cell Line. Cells were seeded into ten $12.5 \mathrm{~cm}^{2}$ cell culture flasks at $4 \times 10^{4}$ cells $/ \mathrm{ml}$ in a
TABLE 2: Cell count of L929 after $72 \mathrm{~h}$ exposure to each HA filler.

\begin{tabular}{lc}
\hline Samples & Cells/ml \\
\hline Filler 1 & 530.00 \\
Filler 2 & 1.355 .000 \\
Filler 3 & 1.150 .000 \\
Filler 4 & 650.000 \\
Filler 5 & 1.005 .000 \\
Filler 6 & 1.555 .000 \\
Filler 7 & 900.000 \\
Filler 8 & 1.145 .500 \\
Filler 9 & 850.000 \\
RC & 1.050 .000 \\
\hline
\end{tabular}

total volume of $5 \mathrm{ml}$ of extraction medium containing sample $(0.2 \mathrm{~g} / \mathrm{ml})$. One flask containing only extraction medium was used as control (RC). Cells were maintained at $+37^{\circ} \mathrm{C} \pm 1$ in a humidified $5 \% \mathrm{CO}_{2}$ atmosphere and monitored daily by using an inverted microscope for $72 \mathrm{~h}$. After $72 \mathrm{~h}$ of incubation, cells were trypsinized and counted by using a Burker camera and Trypan blue staining, in order to evaluate the proliferation rate.

2.6. Haematoxylin/Eosin Staining on the L929 Cell Line. Cells were seeded into 6 -well culture plates at $1 \times 10^{5}$ cells $/ \mathrm{ml}$ ratio in extraction medium containing each sample. Cells were maintained at $+37^{\circ} \mathrm{C} \pm 1$ in a humidified $5 \% \mathrm{CO}_{2}$ atmosphere for $72 \mathrm{~h}$ in order to perform haematoxylin/eosin staining. Briefly, media were removed from each well and cells were washed with PBS and fixed in methanol; $1 \%$ haematoxylin (Sigma-Aldrich) solution was added, followed by PBS washings and $1 \%$ eosin staining (Sigma-Aldrich). Cell morphology was evaluated by using an inverted microscope supplied with a camera (Leica).

\section{Results}

Figure 1 shows results the calculation using the equation (1) for determining cell viability (MTS assay) of L929 exposed to 


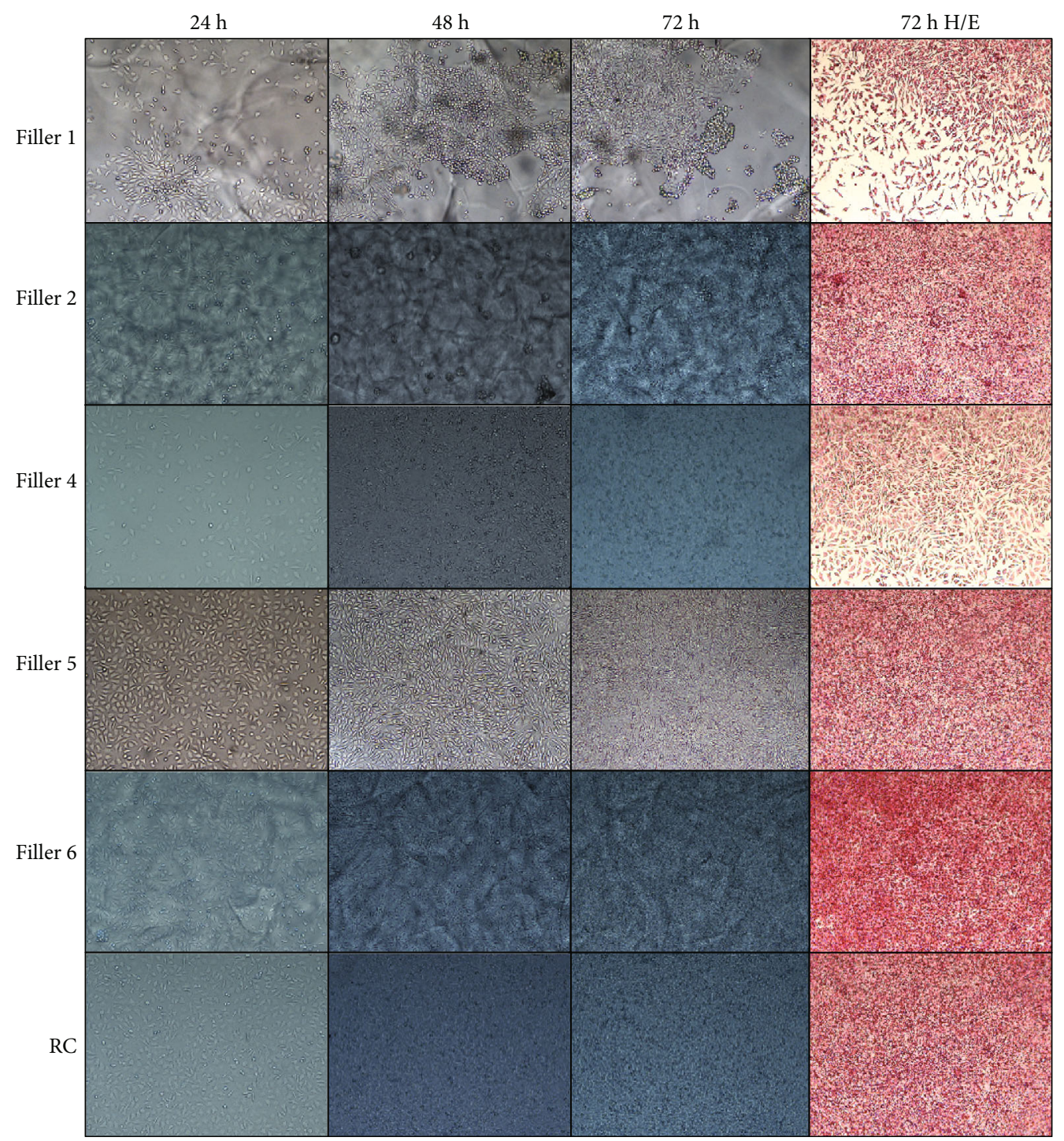

Figure 2: Morphologic evaluation of L929 cells exposed to different HA filler extracts. Observation conduced at $24 \mathrm{~h}$ (first column), $48 \mathrm{~h}$ (second column), $72 \mathrm{~h}$ (third column), and haematoxylin/eosin staining after $72 \mathrm{~h}$ (forth column). Magnification 100x.

the different extracts. The results of cell viability showed that none of the nine fillers analysed had cytotoxic effects on L929 cells at $24 \mathrm{~h}, 48 \mathrm{~h}$, and $72 \mathrm{~h}$, having viability values $>70 \%$. However, filler 2 and filler 6 showed a higher cell viability percentage in comparison to other fillers tested and to the $\mathrm{RC}$ at $72 \mathrm{~h}$, while filler 1 showed the lowest cell viability percentage at $72 \mathrm{~h}$. Phenol solution $0.5 \%$ induced high levels of mortality (viability $<9 \%$ ). Diluted samples induced no cytotoxicity; diluted phenol solution induced cytotoxicity until the $0.125 \%$ concentration (data not shown).

Data obtained from the cell proliferation test are reported in Table 2. Filler 1 and filler 4 showed a lower cell number after $72 \mathrm{~h}$ grown; filler 2 and filler 6 showed an overgrowth of cells suggesting a proliferative effect of these samples on cells; the other samples showed a cell proliferation rate comparable to RC. Figure 2 shows the morphology of L929 when cultured with filler 1 (low cell count), filler 2 (high cell count), filler 4 (low cell count), filler 5 (cell count similar to RC), filler 6 (high cell count), and RC for $24 \mathrm{~h}, 48 \mathrm{~h}$, and $72 \mathrm{~h}$. The last column shows cells stained with haematoxylin/eosin at $72 \mathrm{~h}$. The other samples (fillers 3, 7, 8, and 9) showed a morphology and cell growth similar to RC (data not shown). Moreover, no micorbic growth was observed during the monitoring of cell cultures in contact with the fillers.

\section{Discussion}

In this work, authors report an in vitro study conducted on nine HA dermal fillers among the most commonly used in aesthetic medicine and dermatology, randomly received in the laboratory. According to the UNI EN ISO 10993 regulation, the L929 cell line was chosen for cytotoxicity assay, cell proliferation test, and cell morphology evaluation by haematoxylin/eosin staining. As demonstrated in a previous study, L929 cells are suitable to undergo a cytotoxicity test by MTS assay, as they are sensible to the reference materials indicated in the rule and able to well respond against any cytotoxic substance released in the culture media [12]. The 
MTS assay was chosen due to its low cost, accuracy, rapidity, and reproducibility. In addition, cells were cultured with fillers to evaluate the effects on cell growth in terms of cell count and morphology. These are two simple and rapid methods that, together with MTS assay, could improve the assessment of the biocompatibility of a material designed for human use [18].

Although all samples tested did not shown any cytotoxic effect on L929 cells (cell viability $>70 \%$ ) after $24 \mathrm{~h}, 48 \mathrm{~h}$, and $72 \mathrm{~h}$, two of tested samples (fillers 2 and 6) showed a higher cell viability percentage compared to $\mathrm{RC}$ while other two samples (fillers 1 and 4) showed a lower percentage of viability compared to the same control (Figure 1). Moreover, the samples showed different effects on morphology of cell monolayers and on cell count. After $72 \mathrm{~h}$ of exposition of L929 to fillers, cell count was comparable to the untreated control (RC) for most of the samples, while fillers 1 and 4 showed a cell count reduced by about half and fillers 2 and 6 showed a significant increase in cell count. These results show that, although all examined fillers are not cytotoxic, some of them could have a different in vitro behaviour on cell proliferation by promoting or inhibiting it. These observations were confirmed during the daily monitoring of the monolayers by an optical microscope, since they reached the confluence in different times. Although data on the in vivo effect are not considered in this study, this different behaviour could lead to some in vivo implications in terms of effectiveness of treatment.

In recent years, the use of HA dermal fillers has widely spread in aesthetic medicine and dermatology $[6,19]$. HA is a natural and biocompatible polymer that has a rapid turnover and is quickly degraded by enzymes. To produce a more resistant form of HA, it is cross-linked and stabilized using other substances. According to the cross-linking techniques, HA fillers are classified in monophasic or biphasic [20-22]. Results presented in this study demonstrate that the augment or decrease of the cell number does not depend on the nature of the filler (monophasic or biphasic). Injectable fillers are considered medical devices for which a control by the competent authorities is not required. However, it could be advisable to investigate about their in vitro effects in order to support their safety and to guarantee the absence of risks for the customer. According to the European Directive $63 / 2010 / \mathrm{EU}$, standardized and validated in vitro methods could significantly contribute to limit the use of laboratory animals in biocompatibility tests. Therefore, in that contest, this study shows the suitability of some easy and rapid cellbased methods to assess the biocompatibility and the in vitro effects of HA fillers largely used in aesthetic medicine and dermatology and also predicts a possible in vivo effects in terms of safety and efficacy.

\section{Conclusions}

All HA fillers tested did not shown any cytotoxic effect on L929 cells (cell viability $>70 \%$ ) after $24 \mathrm{~h}, 48 \mathrm{~h}$, and $72 \mathrm{~h}$. Two samples showed a higher cell viability percentage and two samples showed a lower percentage compared to RC. Differences were also found on morphology of cell mono- layers and on cell count. These results show that, although all examined fillers are not cytotoxic, some of them could have different effects on cell proliferation and grown. The easy and rapid assays performed could be useful to test new materials, in terms of cytotoxicity and effects on cells, intended for human use without animal tests.

\section{Data Availability}

The data used to support the finding of this study are available from the corresponding author.

\section{Conflicts of Interest}

The authors declare that they have no conflict of interests.

\section{Authors' Contributions}

Vincenza Cannella and Roberta Altomare have contributed equally to this work.

\section{References}

[1] C. Naoum and D. Dasiou-Plakida, "Dermal filler materials and botulin toxin," International Journal of Dermatology, vol. 40, no. 10, pp. 609-621, 2001.

[2] P. A. Ramires, M. A. Miccoli, E. Panzarini, L. Dini, and C. Protopapa, "In vitro andin vivo biocompatibility evaluation of a polyalkylimide hydrogel for soft tissue augmentation," Journal of Biomedical Materials Research. Part B, Applied Biomaterials, vol. 72B, no. 2, pp. 230-238, 2005.

[3] D. F. Williams, Definitions in biomaterials, Elsevier, Amsterdam, the Netherlands, 1987.

[4] D. F. Williams, "On the mechanisms of biocompatibility," Biomaterials, vol. 29, no. 20, pp. 2941-2953, 2008.

[5] M. Cavallini, P. Molinari, and M. Priori, La gestione degli Errori e delle Complicanze in Medicina Estetica, OEO, 2016.

[6] K. Y. Park, H. K. Kim, and B. J. Kim, "Comparative study of hyaluronic acid fillers by in vitro and in vivo testing," Journal of the European Academy of Dermatology and Venereology, vol. 28 , no. 5, pp. 565-568, 2014.

[7] T. C. Flynn, D. Sarazin, A. Bezzola, C. Terrani, and P. Micheels, "Comparative histology of intradermal implantation of mono and biphasic hyaluronic acid fillers," Dermatologic Surgery, vol. 37, no. 5, pp. 637-643, 2011.

[8] W. Li, J. Zhou, and Y. Xu, "Study of the in vitro cytotoxicity testing of medical devices," Biomedical Reports, vol. 3, no. 5, pp. 617-620, 2015.

[9] V. A. Hampshire and S. H. Gilbert, "Refinement, reduction and replacement (3R) strategies in preclinical testing of medical devices," Toxicologic Pathology, vol. 47, no. 3, pp. 329-338, 2019.

[10] S. Pagano, M. Coniglio, C. Valenti et al., "Biological effects of resin monomers on oral cell populations: despriptive analysis of literature," European Journal of Paediatric Dentistry, vol. 20, no. 3, pp. 224-232, 2019.

[11] International Organization for Standardization, "UNI EN ISO 10993: 2009," in Biological evaluation of medical devices, International Organization for Standardization, Geneva, Switzerland, 2009. 
[12] V. Cannella, R. Altomare, G. Chiaramonte et al., "Cytotoxicity evaluation of endodontic pins on L929 cell line," BioMed Research International, vol. 2019, 5 pages, 2019.

[13] International Organization for Standardization, "UNI EN ISO 10993-5: 2009," in Biological evaluation of medical devicespart 5: in vitro cytotoxicity testing, International Organization for Standardization, Geneva, Switzerland, 2009.

[14] International Organization for Standardization, UNI EN ISO 10993-12: 2009. Biological evaluation of medical devices-part 12: preparation of samples and reference materials, International Organization for Standardization, Geneva, Switzerland, 2009.

[15] S. Pagano, M. Chieruzzi, S. Balloni et al., "Biological, thermal and mechanical characterization of modified glass ionomer cements: the role of nanohydroxyapatite, ciprofloxacin and zinc l-carnosine," Materials Science \& Engineering C, Materials for Biological Applications, vol. 94, no. 94, pp. 76-85, 2019.

[16] S. Pagano, G. Lombardo, S. Balloni et al., "Cytotoxicity of universal dental adhesive systems: assessment in vitro assays on human gingival fibroblasts," Toxicology In Vitro, vol. 60, pp. 252-260, 2019.

[17] "Council Directive 93/42/EEC of 14 June 1993 concerning medical devices," OJ L 169, 12.7.1993, p. 1-43, http://data.europa.eu/ eli/dir/1993/42/oj.

[18] M. Lewandowska-Szumiel, "Alternative methods for assessing biocompatibility and function of implant materials," Alternatives to Laboratory Animals, vol. 27, no. 2, pp. 271-281, 2019.

[19] M. H. Gold, "Use of hyaluronic acid fillers for the treatment of the aging face," Clinical Interventions in Aging, vol. 2, no. 3, pp. 369-376, 2007.

[20] A. Carruthers, W. Carey, C. Lorenzi, K. Remington, D. Schachter, and S. Sapra, "Randomized, double-blind comparison of the efficacy of two hyaluronic acid derivatives, restylane perlane and hylaform, in the treatment of nasolabial folds," Dermatologic Surgery, vol. 31, pp. 1591-1598, 2005.

[21] F. S. Brandt and A. Cazzaniga, "Hyaluronic acid fillers: restylane and perlane," Facial Plastic Surgery Clinics of North America, vol. 15, no. 1, pp. 63-76, 2007.

[22] S. S. Johl and R. A. Burgget, "Dermal filler agents: a practical review," Current Opinion in Ophthalmology, vol. 17, no. 5, pp. 471-479, 2006. 